\title{
Educação de mulheres-mães pobres para uma "infância melhor" *
}

\author{
CARIN KLEIN \\ Rede Municipal de Canoas
}

Contemporaneamente, inúmeras políticas públicas voltadas aos processos de educação e $(m)$ saúde têm tomado a família como foco de suas ações e por meio dela vêm atuando na direção de ensinar especificamente as mulheres, no contexto do exercício da maternidade, sobre como investir na construção de uma "infância melhor". ${ }^{1}$ Acompanhei o trabalho desenvolvido no âmbito de uma dessas políticas - Primeira Infância Melhor (PIM/RS) -, ${ }^{2}$ tal como ela foi implementada em um lócus específico - a cidade de Canoas -, a fim de apreender como o gênero funciona para organizar relações sociais de poder tomando-se por base um conjunto de significados e símbolos construídos. No que concerne às desigualdades de gênero, às discussões sobre as experiências e às formas de intervenção no campo de trabalho pesquisado, esse tema foi/é muitas vezes ignorado, sobretudo quando as ações tomavam/tomam como base enfoques e conhecimentos do campo biomédico e da

* Este texto foi apresentado na 34a Reunião Anual da Associação Nacional de Pós-Graduação e Pesquisa em Educação (ANPEd), 2011, no Grupo de Trabalho Gênero, Sexualidade e Educação (GT-23).

1 Este artigo é um recorte da tese intitulada Biopolíticas de inclusão social e produção de maternidades e paternidades para uma "infância melhor" produzida no âmbito do Programa de Pós-Graduação em Educação da Universidade Federal do Rio Grande do SUL (PPGEdu/UFRGS) (Klein, 2010). A investigação inseriu-se numa agenda de pesquisa mais ampla, coordenada pela professora doutora Dagmar Meyer, no contexto da qual se problematizam, a partir da perspectiva de gênero, conhecimentos e práticas produzidas e/ou implementadas nas áreas da educação e da saúde (Meyer, 2008).

2 No dia 7 de abril de 2003, Dia Mundial da Saúde, o PIM foi lançado pelo então governador do estado do Rio Grande do Sul, Germano Rigotto. Embasado na experiência teórico-metodológica do programa cubano Educa Tu Hijo, tornou-se política pública em 3 de julho de 2006, com a lei estadual n. 12.544/2006. 
psicologia do desenvolvimento, por exemplo. Porém, aqui argumento na direção de que essas formas de saber instituem poderosos regimes de verdade e buscam reger o que deve ser dito e feito, por quem, para quem e em quais circunstâncias.

Nessa perspectiva, este trabalho busca discutir e problematizar como foram produzidos e veiculados alguns ensinamentos direcionados às famílias e como eles posicionavam as mulheres, fundamentalmente, como mães amorosas, educadoras e nutrizes "naturais" e culturais das crianças, responsabilizando-as, quase de forma integral, pela prevenção e cuidado da saúde da família, assim como pela geração da "infância melhor" divulgada pelo PIM. Para realização das análises, utilizo os aportes dos estudos de gênero e culturais, em aproximação com a perspectiva pós-estruturalista. O material empírico da pesquisa foi produzido em um trabalho de campo de caráter etnográfico, por meio do cruzamento de informações de documentos oficiais referentes ao PIM (como o Guia da família), de diários de campo das atividades que integram a política e de entrevistas com visitadoras e mulheres-mães participantes.

O PIM tem como objetivo central "[...] orientar as famílias e gestantes, a partir de sua cultura e experiências, para que promovam o desenvolvimento integral de suas crianças" (Rio Grande do Sul, 2007b, p. 7).

Entre os critérios de seleção das áreas "beneficiadas" pelo PIM, estão o número de famílias cadastradas no Programa Bolsa Família (PBF), menor número de crianças assistidas em escolas infantis, maior taxa de mortalidade infantil e maior vulnerabilidade social, estabelecendo-se, assim, pertencimento ou não.

No que se refere ao PIM, um detalhado aparato pedagógico pretende constituir importantes espaços de veiculação e articulação de estratégias educativas voltadas tanto aos/às profissionais (técnicos/as, monitores/as e visitadores/as) quanto às famílias-alvo. Isso ocorre por meio da elaboração e do uso sistemático de manuais e guias destinados a esses segmentos, bem como por capacitações, visitas domiciliares e reuniões grupais e comunitárias.

Entre as principais estratégias para estabelecer o controle e a intervenção sobre as famílias pobres, está a função do/a visitador/a domiciliar, que necessita:

Realizar o trabalho diretamente com as famílias, orientando-as e capacitando-as para realizar as atividades de estimulação para o desenvolvimento integral da criança, desde a gestação. Orientar as famílias sobre as atividades de estimulação adequadas, a partir do diagnóstico, ou seja, do marco zero. Acompanhar e controlar a qualidade das ações educativas realizadas pelas próprias famílias junto às crianças e as ações realizadas pelas gestantes. [...] Planejar e executar as Modalidades de Atenção Individual e Grupal. (Rio Grande do Sul, 2007b, p. 12)

Assim, o/a visitador/a deve cadastrar, planejar, orientar, desenvolver atividades, elaborar materiais, acompanhar e controlar a qualidade das ações educativas que as famílias devem realizar, promovendo estimulação "adequada" e visando ao desenvolvimento integral das crianças de 0 a 6 anos, desde a gestação. Conhecer a comunidade onde será desenvolvido o PIM, suas características e peculiaridades passam a ser "imprescindíveis" para a realização do trabalho (Rio Grande do Sul, 
2007b, p. 12). Ao ser contratado/a, o/a visitador/a recebe capacitação e cerca de um salário mínimo/mês para acompanhar as crianças e as famílias, residentes em zonas rurais e urbanas, que se encontram em situação de vulnerabilidade social.

Vale dizer que é no(s) campo(s) da educação e(m) saúde que são colocados em ação mecanismos e forças que tratam de definir e conformar modos de ser saudável, cuidador/a e boa mãe. Ê na estreita articulação que se faz entre determinadas formas de exercício da maternidade, vulnerabilidade social e políticas públicas que as mulheres são posicionadas como agentes centrais de operacionalização das políticas que as chamam a responder e a se responsabilizar pelas ações propostas. ${ }^{3}$ Assim, pluralizam-se políticas de Estado que passam a difundir e veicular esse modelo de mulher-mãe, uma vez que as mulheres são o público-alvo das campanhas de cunho educativo e social: programas de aleitamento; recebimento e cumprimento das responsabilidades instituídas pelo PBF; comparecimento em ações voltadas à infância; participação em ações que objetivam a diminuição da violência, programas de planejamento familiar, passeatas de bebês e escolha do bebê mais saudável, entre outras.

Do ponto de vista social, entendo que o PIM, ao priorizar o estímulo ao desenvolvimento integral das crianças de 0 a 6 anos, com ênfase nos primeiros três anos, passa a compor uma estratégia que faz uso de uma discursividade calcada na informação e no monitoramento das famílias de baixa renda, para que sejam capazes de exercer modos específicos de controle e vigilância sobre si. Argumento que propostas governamentais partem do entendimento de que a condução da família (por meio da mãe) é central para o debate que permeia a educação e(m) saúde, responsabilizando principalmente as mulheres-mães pela construção do difundido investimento para uma "infância melhor".

\section{APROXIMAÇÕES ENTRE AS PRÁTICAS EDUCATIVAS DO PIM E A CONFORMAÇÃO DA MÃE-PROFESSORA}

Investigar a produção de conhecimentos que se referem ao desenvolvimento infantil na cultura contemporânea, mais especificamente no conjunto de prescrições formuladas no âmbito do PIM, implica analisar o modo como "verdades científicas" são produzidas e veiculadas e como posicionam "a" mulher e a maternidade no centro das soluções para os problemas que focalizam. Nessa perspectiva, o desenvolvimento "integral" das crianças pressupõe o exercício efetivo das mulheres-mães, exigindo delas sua atenção (também integral), treinamento e monitoramento constantes. Seguir os conhecimentos veiculados no PIM significa usar as "ferramentas" certas. O Guia da família, logo em sua introdução, nos dá algumas pistas sobre como se constrói essa relação:

O uso sistemático deste Guia possibilitará à família o desenvolvimento de suas competências familiares, pois se constitui em uma ferramenta de apoio na construção de vínculos e na promoção do desenvolvimento integral de suas crianças. (Rio Grande do Sul, 2007a, p. 9)

3 Cf. Meyer, 2005; Klein, 2005. 
Ao atentarmos para os jogos de poder e linguagem, pode-se dizer que as proposições do PIM, tanto as descritas nos guias quanto as que compõem as falas dos/as técnicos/as e visitadoras sobre o desenvolvimento infantil, ancoram-se fortemente em pressupostos biomédicos e das teorias psicológicas, partindo de "uma visão em que o contexto é algo enxertado em um modelo único de desenvolvimento [f́sico e] cognitivo" (Walkerdine, 1999, p.16). Deslocar-se da existência desse modelo unitário e fixo pressupõe pensar os sujeitos (mãe e criança) como produtos das linguagens que os nomeiam e que descrevem e significam o seu desenvolvimento numa determinada cultura. Esse movimento requer abandonar, tal como sugere Walkerdine (idem, ibidem), a crença em um sujeito cujo modelo cognitivo seja singular e preestabelecido socialmente, isto é, no qual o desenvolvimento da inteligência (e da saúde) não esteja implicado no apagamento de diferenças de gênero, raça e classe, por exemplo, que o configuram.

Quando pergunto a uma das visitadoras sobre como ela caracterizava as famílias sob sua responsabilidade em relação à situação social e econômica, ela conta a história de uma das famílias que considerava mais carente, composta por uma mulher e três filhas, cujo sustento provinha do PBF. Segundo ela,

$[\ldots]$ a mulher chegava a fazer capina no forte do verão, [...] para poder comprar uma fruta ou alguma coisa para as gurias comerem, que tinham fome, e terminava a capina, e não pagavam a coitada. (Renata, ${ }^{4} 4$ jul. 2007)

Diante disso, pergunto ainda sobre seus sentimentos (ou impressões) quando necessitava ensinar-lhe higiene, cuidado, saúde e organização do lar, por exemplo, uma vez que percebia que essa mulher-mãe não tinha, muitas vezes, alimentos suficientes para alimentar a si e as filhas.

Era muito complicado... Eu até tive dificuldade... Foi quando eu comecei a trabalhar com as meninas dela sobre saúde bucal. "Ah, mas tem dias que eu não tenho o que comer, vou ter pasta de dente das meninas?” [Renata refere-se à mãe das meninas]. Daí, eu trabalhei com ela. Tem outra forma: não tem pasta de dente? Escovinha e água. [...] E tentava achar outro jeito com ela, para ela não se basear; porque não tem, não vou escovar meus dentes? Mas tem outra maneira: não tem hoje, amanhã ou o dia que tiver, com a escova, a pasta. E o dia que não tiver, água e escovinha... Está tranquilo. Mas é bem complicado trabalhar higiene se não tem sabonete, roupa limpa, se não tem sabão para lavar a roupa. (Renata, 4 jul. 2007)

O excerto nos faz pensar em como as orientações do cuidado se materializam nas ações das visitadoras, em que as noções do desenvolvimento infantil parecem seguir uma linearidade, sistemática e progressiva, talvez muito diferente dos interesses e experiências de algumas famílias em questão. A visitadora demonstrava reconhecer que essa mulher-mãe, com a "capina no forte do verão", tentava trabalhar para alimentar as filhas. Entretanto, logo adiante, ao falar sobre as tarefas relativas ao PIM, como escovar os dentes, dizia que precisava insistir com a mãe para "ela não se basear". Fica implícita

4 Esclareço que todos os nomes citados são fictícios. 
a compreensão da visitadora de que necessitava cumprir o seu trabalho educativo por pressupor que, em um contexto de pobreza, o não cumprimento de determinadas tarefas pudesse ocorrer por ignorância, preguiça ou acomodação. Esse raciocínio pressupõe de antemão um lugar de falta ou de "quem é faltoso" e precisa de intervenção (Paraiso, 2011).

De acordo com o que era difundido pelo PIM, presente na fala da visitadora, o cuidado adequado e a expressão do amor materno estavam atrelados à higiene bucal e corporal, a um modo de brincar, conversar e oferecer um ambiente tranquilo para as crianças. Já, para aquela mulher-mãe, realizar tarefas ligadas ao cuidado e ao amor, naquelas circunstâncias de carência, possivelmente implicasse a realização de uma atividade laboral, a busca cotidiana por um trabalho capaz de garantir o alimento daquele dia. É a partir daquilo que escapa do modelo de educação e de cuidado veiculado no âmbito do PIM que se pode pensar no posicionamento esperado de mulheres-mães que vivem num contexto de extrema pobreza - trata-se de algo que direciona de outro modo suas ações e as faz ter compreensões e possibilidades diferentes de exercitar o "cuidar e amar".

Provavelmente, aprender assuntos que envolvem higiene, alimentação, cuidado e desenvolvimento infantil dependerá da inserção social e econômica dos sujeitos envolvidos, reconhecendo-se que cada cultura ou contexto social significa diferentemente os processos de educação e $(\mathrm{m})$ saúde. A visitadora diz "está tranquilo", referindo-se ao que ela precisava ensinar sobre higiene, para logo em seguida dizer "mas é bem complicado trabalhar", apontando em sua fala a tensão existente entre as formas como algumas "verdades" eram dirigidas a famílias ou a mulheres que possuíam dificuldades muito concretas em realizar o que lhes era proposto. Isso, possivelmente, perturbava referências e teorizações organizadas e centradas em um sujeito unitário e racional e em um conjunto de ensinamentos formulados com base nessas crenças.

Nessa linha, seria possível questionar a suposta "natureza" do desenvolvimento infantil e do cuidado relacionado à maternidade, principalmente ao se explorar argumentos que mostram a contingência e a provisoriedade dessas categorias, localizando-as em posições sociais, históricas e políticas diferentes (Walkerdine, 2007). Nesse sentido, localizo fragmentos discursivos da psicologia do desenvolvimento (e representações de gênero) que embasavam os ensinamentos presentes nos documentos e que, além de constituírem o PIM, norteavam as orientações e atividades desenvolvidas pelas visitadoras e as famílias, essas representadas em sua maioria pelas mulheres-mães.

O Guia da família foi elaborado para utilização das famílias, dando-lhes sugestões de atividades, "de acordo com a faixa etária e conforme suas necessidades, proporcionando seu desenvolvimento integral” (Rio Grande do Sul, 2007a, p. 9). Atividades, cuidados, brincadeiras, estímulos e características da criança de 0 a 6 anos são descritos no guia, buscando o "desenvolvimento integral e o crescimento saudável e feliz da criança, que deve ser rodeada de carinho e da compreensão de todos" (idem, ibidem). Para isso, o guia traz "quadros que indicam os ganhos do desenvolvimento da criança”, com o propósito de que as famílias saibam "o que esperar que ela faça ou consiga realizar sozinha, ou com o auxílio de seu cuidador, ao final de cada etapa da vida" (idem, ibidem). Vejamos, por exemplo, como são descritas as atividades que a criança "pode fazer" ao final dos 12 meses, como mostram as orientações a seguir: 
Quadro 1- Indicadores do desenvolvimento ao final dos 12 meses de vida

Guia da família
Conforme tabela abaixo, observe o que o seu filho pode fazer ao final dos doze meses de vida. Caso haja
algo que não tenha conseguido fazer ou que faça com insegurança, não se preocupe. Continue realizando
as atividades diariamente, com carinho, e logo ele estará fazendo.

\begin{tabular}{|l|l|l|l|}
\hline \multicolumn{1}{|c|}{ INDICADORES } & $\begin{array}{c}\text { Consegue } \\
\text { fazer sozinho }\end{array}$ & $\begin{array}{c}\text { Consegue } \\
\text { fazer com } \\
\text { ajuda }\end{array}$ & $\begin{array}{c}\text { Ainda não } \\
\text { consegue } \\
\text { fazer }\end{array}$ \\
\hline Dá pequenos passos sozinho & & & \\
\hline Segura um brinquedo enquanto caminha & & & \\
\hline Manuseia, atira e pega brinquedos & & & \\
\hline $\begin{array}{l}\text { Pode fazer coisas simples, como } \\
\text { ninar uma boneca ou passear com } \\
\text { um bichinho de brinquedo }\end{array}$ & & & \\
\hline Tampa e destampa caixas para pegar brinquedos & & & \\
\hline $\begin{array}{l}\text { Cumpre pequenas ordens, como } \\
\text { "pega o brinquedo" ou "me dá" }\end{array}$ & & & \\
\hline Pronuncia algumas palavras & & & \\
\hline Bebe segurando o copo com a própria mão & & & \\
\hline
\end{tabular}

Fonte: Rio Grande do Sul (2007a, p. 31).

Nesse contexto, localizamos a criança ativa e exploradora do PIM, que passa a ser examinada e entendida de acordo com sua evolução "natural" e a ser descrita, detalhada e classificada (Walkerdine, 2007). Como vemos, é numa ordem sucessiva e num tempo cronológico que a criança precisa desenvolver sua cognição e expandir seu desenvolvimento motor e de linguagem. Entender quem é essa criança significa conhecer e seguir o que é proposto para cada fase. Sendo assim, pressupõe-se um ponto de partida e de chegada, e o projeto da "infância melhor" preconizada pelo PIM encaixa-se nessa ordem específica. No âmbito dessas coordenadas, em oposição ao desenvolvimento infantil sadio, aparece a noção de déficit, em que se torna necessário pensar o que falta a criança alcançar para a produção do projeto de infância ali delineado, cujo desenvolvimento deve ser linear e progressivo.

Os “indicadores" de desenvolvimento, assim como outras orientações do guia, são descritos numa linguagem bastante didática e devem servir como referência para a avaliação constante e periódica das mulheres-visitadoras e da equipe técnica. Nesse sentido, tratam de ensinar e orientar as mulheres-mães a ocuparem uma posição de sujeito capaz de seguir uma rotina diária de atividades, brincadeiras e estímulos. Desse modo, os "indicadores" do desenvolvimento propostos pelo guia convergem com os "ditos evolutivos", que estruturam medidas objetivas, observações e intervenções das mulheres-mães para com as crianças, de maneira que elas se preocupem com a velocidade e o progresso do "desenvolvimento normal", concedendo uma espécie de "prestígio cultural" aos mais adiantados e "castigos reais" subjetivamente atribuídos aos mais atrasados (Burman, 1999, p. 81-82). 
A descrição e a análise de alguns documentos tornaram-se importantes para mostrar como eles são constitutivos das ações que se materializavam nas atividades que vivenciei, tanto com as visitadoras e mulheres-mães quanto com os/as técnicos/as e visitadoras. O Guia da família traz orientações para diferentes períodos da infância: até 1 ano, os ensinamentos são organizados em períodos trimestrais; depois desse período, são anuais. Cada período do desenvolvimento infantil está descrito com orientações específicas, indicando o que a criança já é capaz de fazer em cada idade. Por fim, apresenta-se a tabela com os indicadores de cada período, em que "a 'natureza da criança' passa a ser o fundamento de toda a prática educacional, dirigida ao monitoramento, à observação e à facilitação da sequência do desenvolvimento" (Walkerdine, 2007, p. 21).

A indagação "O que você pode fazer para que seu filho cresça e se desenvolva forte e feliz?”, uma das seções organizadas no guia, pressupõe um entendimento de que todas as mulheres-mães precisam aceitar e mergulhar em conhecimentos a fim de aprender o que fazer para que as crianças cresçam felizes. Ao perguntar às mulheres-mães sobre suas aprendizagens mediante a adesão ao PIM, Marta me respondeu:

Eu aprendi um monte, um monte... Tipo assim, uma que eu não tinha tempo para elas. Com a maior, eu não brincava e deixava no carrinho, botava ali e ali deixava, não fazia carinho, brinquedo, aquele negócio de fazer brinquedo com materiais... Eu não fazia. E, com ela, não. Com ela, eu aprendi um monte de coisa, como aquela calça que a gente enche de pano ou jornal e coloca a criança no meio para ela ficar sentadinha e não cair. (Marta, 1 ago. 2007)

Essa fala nos faz refletir sobre o valor social atribuído à mulher por meio do exercício da maternidade, pelo cumprimento de normas capazes de determinar, por exemplo, a posição que as mulheres-mães pobres precisavam ocupar na educação das crianças, ou seja, como "principal fonte de amor, de segurança e de estímulo" (Rio Grande do Sul, 2007a, p. 21). Os enunciados expressos nas orientações dirigidas às famílias, seja nos guias, seja na prática das visitadoras e técnicos/as, indicavam a existência e a necessidade de uma mulher-mãe em casa, dotada de tranquilidade, sensibilidade, criatividade, cuidados, atenção e, fundamentalmente, vontade de aprender, tal como Marta demonstrava ter incorporado.

Nesse contexto educativo, vejamos como a mulher-mãe é posicionada no Guia da familia:

O conhecimento do espaço onde vive é importante para o desenvolvimento do seu filho. Entende-se como espaço o bairro onde vive, sua casa, pátio, cozinha etc. A relação com os objetos no espaço pode ser trabalhada de modo simples, como as seguintes determinações: Busque o livro que está debaixo da mesa. Pegue a camisa que está na gaveta direita. [...] Existe uma brincadeira que toda criança gosta. Mamãe mandou: levantar a mão direita; levantar a perna esquerda; tocar o olho esquerdo [...] as ordens podem variar de acordo com o desenrolar da brincadeira. Assim como podem partir da criança e você cumpri-las. (idem, p. 68-69) 
O excerto visibiliza a produção de uma pedagogia centrada na criança, instituindo a posição de sujeito de "mãe-professora", capaz de atuar em casa, no pátio, na cozinha - uma mãe que necessita estudar o guia para aprender a brincar com as crianças, explorar o espaço, realizar atividades motoras. A "mãe-professora" é quem deverá suprir a ausência de uma educação infantil de qualidade que não está ao alcance de muitas famílias pobres brasileiras. O que importa nesta discussão não é colocar em xeque o que "realmente" as crianças precisam ou devem aprender, mas analisar de que forma os ensinamentos propostos por meio do PIM são atravessados por pressupostos de pertencimento social e gênero. Isso porque produzem e agregam valor social ao trabalho feminino, uma vez que essas "verdades" são constantemente reafirmadas, tanto no âmbito de políticas públicas quanto na mídia, salas de aula, consultórios médicos, postos de saúde, guias, manuais e campanhas educativas. Porém, esse trabalho ou "função social" não é apresentado e ensinado da mesma forma para homens e mulheres, pois se enfatiza que é a mãe quem deve brincar e ensinar noções corporais e de espaço aos/às filhos/as.

A mulher, ao ser convocada a ocupar a posição de "mãe-professora", precisava evidenciar a presença e a compreensão de determinados atributos que a transformariam em referência para a realização de ensinamentos cujo propósito era garantir o desenvolvimento infantil saudável. Para a concretização desses objetivos, é enunciado de forma exaustiva que, "com a sua dedicação e ajuda, seu filho já pode [ou poderá] fazer muitas coisas" (idem, p. 27). De acordo com o Guia da família, a dedicação, a ajuda e o estímulo que a família (por intermédio da mãe) deve despender também precisam combinar-se com amor e atenção constantes:

Dê amor a seu filho: Toda criança precisa ser amada e aprender a confiar. Demonstre segurança e carinho a seu filho através de abraços e beijos. Procure olhar nos olhos do seu filho durante todo o tempo que você estiver lidando com ele. Isto é muito importante para o fortalecimento da relação afetiva. Fale com ele com voz suave e sorria durante a amamentação, banho, troca de fraldas e roupas e em todas as atividades que realizar. (idem, p. 10)

Talvez o amor e o cuidado possam servir como temas para a realização de discussões capazes de revelar a ambiguidade, a fluidez e a transitoriedade presentes nas vivências humanas, abarcando indagações do tipo: o amor materno requer uma mulher abnegada e trabalhando em tempo integral em favor de seus/suas filhos/as? Quais os efeitos da vinculação do desenvolvimento infantil a uma determinada representação de amor materno que deve ser experienciado pelas mulheres pobres? A produção de uma pedagogia que exalta o posicionamento da mulher como educadora e cuidadora e uma suposta entrega que deve ser realizada quando se ama fazem com que o sentimento de amor passe a funcionar como uma forma de controle e de regulação (Felipe, 2007), reforçando o argumento apresentado no excerto, de que a mulher, "em todas as atividades que realizar", necessita ser "suave, alegre e amorosa", mesmo quando estiver dando banho, amamentando e trocando as fraldas e roupas do bebê. Nesse contexto, há pouco ou quase nenhum lugar para a coexistência de sentimentos negativos ou contraditórios por parte das mulheres, 
levando-as a compreender que externá-los pode significar julgamento e reprovação social e, acima de tudo, prejuízo para o desenvolvimento saudável de seu/sua filho/a.

Se pensarmos nos discursos veiculados pelo PIM, que elege como público-alvo famílias que vivem em situação de vulnerabilidade social e cujo eixo justificador se ancora nas ações que prescreve para reduzi-la, perceberemos que muito pouco é oferecido por parte do Estado para que as pessoas em questão possam responder de maneira que ultrapassem obstáculos materiais, culturais e políticos que possivelmente contribuem para mantê-las vulneráveis. Mais do que atuar na cultura e sobre as relações familiares, ensinando as pessoas a "ensinar com amor" ou a "adotar hábitos saudáveis", talvez fosse necessário buscar compreender um conjunto mais amplo de forças que operam na configuração de valores, conhecimentos e formas de viver em relação à educação $\mathrm{e}(\mathrm{m})$ saúde, assim como na possibilidade concreta ou não de transpor situações estruturais e de pobreza.

Políticas públicas, como o PIM, apoiam-se em retóricas que, de um lado, posicionam as mulheres como sujeitos que necessitam ser reiteradamente ensinados, ao mesmo tempo em que, de outro, indicam o amor como uma dimensão inerente à mulher e à família, algo que deve ser vivenciado em qualquer época e lugar. Nessa linha, torna-se recorrente, tanto no guia quanto nas ações de seus atores: "Dê afeto! Lembre-se que a família é a principal fonte de amor, de segurança e estímulo"; "O afeto é a base para tudo que a criança aprende” (Rio Grande do Sul, 2007a, p. 21); "Você já sabe que seu filho precisa sentir o carinho de todos que o rodeiam. Fale com ele com doçura, sorria e beije" (idem, p. 22).

Nas ciências sociais e humanas, o amor torna-se alvo de estudos sistemáticos, na medida em que vem ocupando um lugar central nas relações sociais (Britzman, 1996; Felipe, 2007; Giddens, 1993; Neves, 2007). Desse modo, dinâmicas familiares e conjugais, assim como as vivências da maternidade e da paternidade, podem ser analisadas por esse prisma, a fim de apreender algumas formas pelas quais o amor passa a ser significado e articulado às relações entre gênero, pobreza e vulnerabilidade. Argumento que o amor não é um sentimento abstrato, universal e homogêneo, mas definido como um construto da cultura, e que sua valoração ocorre de acordo com significados partilhados socialmente. Em nossa cultura, amor, assim como abnegação, paciência, culpa, sofrimento e dor, tem sido insistente e reiteradamente associado ao feminino e à maternidade.

No exame da produção de uma semântica para a maternidade com e por meio do PIM, o amor materno também se destaca como um sentimento que, paradoxalmente, é apresentado como sendo inerente ao feminino, ao mesmo tempo em que precisa ser aprendido e expressado de determinadas formas; ele passa a funcionar como um meio de regulação e controle, constituindo-se com a formulação de códigos, regras e condições associadas a interesses institucionais e políticas sociais. Constituídos e constituintes nas relações sociais, os discursos veiculados no âmbito de políticas públicas como o PIM, produzidos em torno do amor, da infância e da maternidade, podem abarcar a configuração da relação mãe-filho/a: aproximando-os/as, afastando-os/as, rearranjando.

Isso me permite argumentar que diferentes formas de viver a feminilidade e a maternidade podem coexistir, cabendo indagar sobre quais feminilidades são 
ou podem se manifestar no espaço do PIM, uma vez que há representações de maternidade aceitáveis, desejáveis e naturais, enquanto outras são classificadas como inaceitáveis, indesejáveis e antinaturais (Dal'igna, 2005). Desse modo, podemos pensar na articulação entre gênero e pobreza, especialmente quando se ensinam e se posicionam mulheres pobres como mães-professoras para torná-las "capazes" de educar e cuidar de seus/suas filhos/as - isso sem esquecer que as mulheres que precisam ser ensinadas são as que possuem baixa escolaridade, não pertencem ao mercado de trabalho formal e são excluídas de "direitos sociais", como licença-maternidade e, em muitos casos, não tendo acesso à educação infantil para os filhos, por exemplo. Fica nas entrelinhas que as mulheres pobres precisam aprender uma forma específica de amar e demonstrar esse amor pelas crianças, principalmente pela adesão a determinados hábitos, que incluem: alimentar, higienizar, organizar horários e rotinas, estimular, além de outras formas específicas de cuidar das crianças.

No contexto das políticas públicas de inclusão social, o uso dessa retórica específica de amor materno passa a atuar como propulsor de desenvolvimento infantil e de relações interpessoais saudáveis de crianças pobres e suas famílias. Tal entendimento pretende reforçar relações e experiências familiares por meio da vinculação com a educação e o desenvolvimento infantil e levar as mulheres a exercerem "melhor" a sua função de cuidadoras. Pode-se pensar que a criança se torna o objeto do amor materno, "encarado sob o ponto de vista da ordem e do dever sociais" (Giddens, 1993, p. 48), que necessita ser vivenciado, fundamentalmente, pelas mulheres. A mãe-professora deveria, ainda, tornar-se capaz de experimentar a vivência do sentimento de amor e da emoção, formando uma espécie de fusão com as demais tarefas eleitas para esse cotidiano.

Ao realizar as entrevistas com as visitadoras, buscava entender como elas compreendiam a situação social das famílias atendidas nos diferentes contextos físicos em que circulavam. A conversa com a visitadora Luísa trouxe-me mais pistas para refletir sobre as relações sociais que se estabeleciam e abarcavam tanto os ensinamentos do PIM quanto as formas de viver e organizar-se de famílias em situação de pobreza. Ao perguntar sobre como suas famílias se mantinham, ela respondeu:

Da reciclagem, na maioria das vezes. Os pais trabalhavam em bicos, era uma obra, uma capina, um limpa pátio, esses bicos que eles faziam e até muitas das mães também. Era fazer uma faxina ou até mesmo artesanato, crochê ou tricô, só que aquilo que tu tens que ter um dinheiro para investir, muitas vezes, ou compras um novelo de linha ou um quilo de arroz.

O que significa ser pobre a partir daquilo que você vivenciou? É bem difícil... Eu acho que pobres mesmo são aquelas pessoas que tentam, que lutam e que não têm um emprego fixo de carteira assinada, lutam todo dia para ter o pão, saem de manhã catando lixo na rua, para chegar de noite e tentar vender alguma coisa para ter o que dar de comida para os filhos, porque muitas vezes as pessoas se julgam pobres, mas elas têm o arroz, o feijão, o açúcar, elas têm uma cama seca para dormir, e muitas das vezes essas outras famílias que são 
pobres mesmo, elas não têm isso, porque, num dia de chuva, molha tudo dentro de casa, porque tu não tens condições de arrumar o teto, de trocar o telhado, tu não tens condições de ter uma água encanada, porque tu não tens uma renda. (Luísa, 24 jul. 2007)

Ao falar sobre uma de suas famílias e o que ela entendia por pobreza, Luísa não se referiu aos ensinamentos do PIM, não responsabilizou as mulheres-mães e também não chamou a atenção para aspectos que elas pudessem negligenciar. Naquelas circunstâncias, os argumentos em torno de um "modo natural de ser mulher e mãe" ou da "mãe desnaturada" talvez se mostrassem irrelevantes. Mesmo sem dizer nada, parecia que sabíamos que as possíveis "faltas ou falhas" em relação ao cuidado, à educação das crianças e, eu diria, à integridade e manutenção tanto das crianças quanto de muitas famílias não dependiam apenas do controle ou da responsabilização das mulheres. Naquele momento, muitas "lições" pareciam cair por terra, trazendo "tensões" profundas que atravessavam (e iam muito além de) alguns entendimentos e propostas governamentais. O excerto também nos faz refletir sobre o caráter relacional da pobreza: Luísa indicava que, para referir-se a uma família "pobre mesmo", ela precisava tomar um determinado contexto ou a vivência de outras famílias como ponto de referência, que, em tais circunstâncias, provavelmente eram aquelas que não necessitavam catar lixo o dia todo para depois ter o que comer.

Uma reflexão importante sugere que a discursividade presente nas políticas públicas expressa geralmente uma única versão sobre a pobreza e a forma de viver das pessoas pobres, representada repetida e exclusivamente como o lugar da falta (ou da ignorância). Pode-se dizer que a metodologia apresentada no contexto da política revela uma forma de educar, cuidar, organizar-se e responsabilizar-se que cria poucas oportunidades para que as pessoas em questão (tomadas como vulneráveis) também possam indicar as suas formas de educar, criar recursos e viver. Nessa relação de poder, produz-se não apenas uma hierarquia entre o que conta ou não como verdade, mas negam-se ou tornam-se irrelevantes as experiências do "outro", restando pouco ou nenhum espaço para a interlocução.

No que se refere à discussão de gênero, conhecimentos acerca do cuidado e do desenvolvimento infantil não podem ser vistos como neutros. Walkerdine (1999) argumenta que pensar nas dificuldades vividas por crianças pobres como decorrência da falta de cuidado das mães é um enfoque problemático, pois sugere que essas dificuldades resultam de um tratamento inadequado por parte das mulheres. Como a autora indica, tal abordagem deixa de lado a complexidade do social, ocorrendo uma dissociação entre aprendizagem e dimensões culturais, como as de classe, raça, gênero e geração, por exemplo.

Como principais fontes de um amor "verdadeiro" e abnegado, as mulheres e a maternidade passam a ser associadas diretamente ao lar e à intimidade, que inclui a organização da vida familiar e a criação dos/as filhos/as. Assim, uma mulher "responsável" precisa protagonizar histórias que ilustrem esses pressupostos. Quando pergunto a outra visitadora sobre os aspectos que ela considera importantes para facilitar ou dificultar o desenvolvimento infantil, ela sugere: 
Eu acho que dificulta quando a mãe não dá muita importância e atenção, não conversa com a criança. Muitas vezes, as mães estão olhando televisão e deixam a criança de lado, chorando no carrinho, sem iniciativa de ver se o bebê está mijado ou se está chorando por alguma dor. Tem mães que não têm esse interesse, e eu acho que isso dificulta bastante. Assim, quando o PIM entra, começa a visitadora a conversar com a mãe: "Como está o bebê?”, "Está bem de saúde?”, "O que tu fizeste hoje com o teu bebê?”, "Tu pegaste teu filho no colo, conversaste com ele?” A gente fala na importância da criança para a mãe, começa a ensinar que é importante o afeto, a amamentação. É o vínculo entre a mãe e o bebê! (June, 23 jul. 2007)

O excerto assinala situações em que a criança "fica de lado" e a mulher-mãe "não tem iniciativa e interesse". Nesse contexto, analisar os sentidos agregados à noção de "mães problemáticas" decorre da avaliação do que é descrito como interesse, sensibilidade diante das necessidades da criança, tempo disponível para brincar, recursos que mobilizam, enfim, o espaço que as mães criam e ocupam para cuidar e educar. A interação e a ligação mãe-bebê pressupõem que o lugar central seja ocupado pelo bebê, enquanto a mãe precisa deixar de lado suas próprias necessidades e interesses, também deixando de fora dessa relação os conflitos que lhe são inerentes (Woollett; Phoenix, 1999).

A teoria da ligação afetiva, apoiada em estudos como os elaborados por John Bowlby e Donald Winnicott em um contexto de pós-guerra, considera que a mãe não só deveria acompanhar constantemente o/a seu/sua filho/a, como também encontrar sua realização pessoal por meio disso. A ênfase desses estudos recaía sobre os efeitos que a privação materna acarretava: distúrbios emocionais, psicológicos e de caráter, desde a criação da delinquência e insuficiência no desempenho escolar até adultos incapazes de relacionar-se socialmente. Nessa linha, a ligação mãe-bebê é considerada tanto natural e intuitiva quanto central para o desenvolvimento de seres humanos saudáveis, relegando os homens-pais a um lugar de quase nenhum destaque (Klein, 2005, 2010).

Se considerarmos o gênero como um organizador das relações sociais, poderemos pensar que, quando as mulheres-mães passam a ser ensinadas e responsabilizadas integralmente pelo desenvolvimento infantil, ocorre a formação de um processo de generificação que traz especificidades. Esse processo não só atrela o conhecimento do cuidado, do afeto, do desenvolvimento da inteligência e da aquisição da linguagem a comportamentos e desempenhos femininos, mas também os constitui. Segundo Burman (1999), a psicologia evolutiva não apenas elenca os assuntos mais relevantes que envolvem a infância, a maternidade e as práticas profissionais, como também segmenta a vida, de tal maneira que o desenvolvimento da primeira infância seja descrito como um período determinante para a vida adulta.

Pode-se dizer que a noção de déficit tem correlação direta com a noção de diferença. A valorização das mulheres e do feminino, como vimos no excerto, passa a ocorrer a partir de respostas como: iniciativa em pegar no colo, brincar, cuidar da alimentação, horas de sono, higiene bucal e corporal, desenvolvimento do pensamento e da imaginação - ensinamentos propostos pelo PIM em relação às crianças. Como patológicos ou desviantes, estariam os comportamentos que diferem ou se afastam do que é proposto como ideal, ou seja, estariam vinculados a uma 
maternidade que não corresponde aos ensinamentos propostos: não ter interesse, não dar atenção para a criança, deixar de lado ou "mijado".

Podemos, ainda, destacar a relação entre aprendizagem e as noções de "ambiente natural" e de "mundo ordenado", que seguem na base das proposições do PIM, em que a criança e seu desenvolvimento "normal" são centrais, enquanto a mãe é posicionada como a pessoa mais adequada para efetivar essa relação, necessitando estar aberta a ser ensinada, avaliada, regulada e monitorada. Desse modo, investir no desenvolvimento infantil, na grande maioria das políticas públicas de educação e(m) saúde e/ou de inclusão social, implica trabalhar na construção de uma família=mãe e de uma "mãe professora" capaz de aprender a organizar-se, colocar desafios às crianças de acordo com os ensinamentos propostos, seguir regras de conduta. Isso quer dizer que as mulheres devem cumprir determinadas tarefas, tanto no que se refere à alimentação, higiene e cuidado quanto em relação a formas de lazer, educação, consumo e, sobretudo, formas de amar.

Quero terminar parafraseando Scott $(2005$, p. 29), quando ela argumenta que o que faz sentido é produzirmos indagações do tipo: "como os processos de diferenciação social [se formam e] operam?”O investigações que examinem como os processos que envolvem a pobreza, o gênero e a desigualdade se instituem e se tornam efeitos de configurações sociais mais amplas (que envolvem a política) marcadas pela desigualdade.

\section{REFERÊNCIAS}

Brasil. Lei n. 10.836, de 9 de janeiro de 2004. Programa Bolsa Família. Disponível em: <http://www.planalto.gov.br/ccivil_03/_Ato2004-2006/2004/Lei/L10.836.htm>. Acesso em: 5 ago. 2011.

B RITZMAn, Deborah. O que é essa coisa chamada amor: identidade homossexual, educação e currículo. Educação \& Realidade, Porto Alegre, Faculdade de Educação/UFRGS, v. 21, n. 1, p. 71-96, jan./jun. 1996.

Burman, Erica. La desconstrucción de la psicología evolutiva. Madrid: Vision, 1999.

Daligna, Maria Claudia. "Há diferença"? Relações entre desempenho escolar e gênero. 2005. Dissertação (Mestrado em Educação) - Universidade Federal do Rio Grande do Sul, Porto Alegre, 2005.

FeLipe, Jane. Do amor (ou como glamourizar a vida): apontamentos em torno de uma educação para a sexualidade. In: Ribeiro, Paula Regina Costa et al. (Orgs.). Corpo, gênero e sexualidade: discutindo práticas educativas.1.ed.,v.1. Rio Grande, RS, Editora da UFRGS, 2007. p. 31-45.

Fonseca, Claudia. Algumas reflexões em torno do "abandono materno". In: Tornquist, Carmen et al. (Orgs.). Leituras de resistência: corpo, violência e poder. v. II. Florianópolis: Ed. Mulheres, 2009. p. 49-80.

Giddens, Anthony. A transformação da intimidade: sexualidade, amor e erotismo nas sociedades modernas. São Paulo: Editora da Universidade Estadual Paulista, 1993.

KLein, Carin. A educação de mulheres como mães e professoras no Programa Nacional Bolsa Escola. Educação E̊ Realidade, Porto Alegre, Faculdade de Educação/UFRGS, v. 30, p. 223-251,jan./jun. 2005. 
. Biopolíticas de inclusão social e produção de maternidades e paternidades para uma "infância melhor". 2010. Tese (Doutorado em Educação) - Universidade Federal do Rio Grande do Sul, Porto Alegre, 2010.

Meyer, Dagmar. A politização contemporânea da maternidade: construindo um argumento. Gênero, Niterói, Núcleo Transdisciplinar de Estudos de Gênero (NUTEG), v. 6, n. 1, p. 81-104, jul./dez. 2005.

. et al. A educação "da família" como estratégia governamental de inclusão social: um estudo situado na interface dos estudos culturais, de gênero e de vulnerabilidade. Porto Alegre: UFRGS/CNPq (Relatório de pesquisa). Porto Alegre: Faculdade de Educação, UFRGS, 2008.

Neves, Ana Sofia Antunes das. As mulheres e os discursos genderizados sobre o amor: a caminho do "amor confluente" ou o retorno ao mito do "amor romântico"? Estudos Feministas, Florianópolis, UFSC, v. 15, n. 3, p. 609-626, set./dez. 2007.

Paraiso, Marlucy Alves. Raciocínios genereficados no currículo escolar e possibilidades de aprender. In: Leite, Carlinda et al. (Orgs.). Políticas, fundamentos e práticas do currículo. Porto: Porto Editora, 2011.v.1, p. 147-160.

Rio Grande do Sul (Estado). Lei estadual n. 12.544, de 3 de julho de 2006. Institui o Programa Primeira Infância Melhor-PIM. Porto Alegre, RS, Ministério Público. Disponível em: <http:/www.mp.rs.gov.br/infancia/legislacao/id3192.htm>. Acesso em: 5 ago. 2011.

. Secretaria da Saúde do Estado do Rio Grande do Sul. Programa Primeira Infância Melhor. Guia da família. 2. ed. Porto Alegre: Relâmpago, 2007a. 84 p.

. Secretaria da Saúde do Estado do Rio Grande do Sul. Programa Primeira Infância Melhor. Guia de orientação para GTM, monitor e visitador. Contribuições para políticas na área do desenvolvimento infantil. Porto Alegre: Relâmpago, 2007b. 70 p.

Scott, Joan. O enigma da igualdade. Estudos Feministas, Florianópolis, UFSC, v. 13, n. 1, p. 11-30, 2005.

Walkerdine, Valerie. Diferença, cognição e educação matemática. Estudos Leopoldinenses, São Leopoldo, Unisinos, v. 3, n. 4, p. 7-19, jan./jun. 1999. (Série Educação).

. Ciência, razão e a mente feminina. Educação $\mathcal{E}^{2}$ Realidade, Faculdade de Educação da Universidade Federal do Rio Grande do Sul, Porto Alegre, v. 32, n. 1, p. 7-24, jan./ jun. 2007.

Woollett, Anne; Phoenix, Ann. La maternidad como pedagogía: la psicología evolutiva y los relatos de madres de niños pequeños. In: Luke, Carmen (Org.). Feminismos y pedagogías en la vida cotidiana. Madrid: Morata, 1999.

\section{SOBRE A AUTORA}

Carin Klein é doutora em educação pela Universidade Federal do Rio Grande do Sul (UFRGS). Funcionária da Rede Municipal de Canoas. E-mail: carink@terra.com.br 


\section{CARIN KLEIN}

\section{Educação de mulheres-mães pobres para uma "infância melhor"}

Este artigo analisa a veiculação e produção de alguns ensinamentos direcionados a famílias pobres e como eles posicionavam as mulheres, fundamentalmente, como mães amorosas, educadoras e nutrizes "naturais" e culturais das crianças, responsabilizando-as, quase integralmente, pela prevenção e cuidado da saúde da família e pela geração da "infância melhor". Os dados etnográficos foram obtidos no contexto de uma política pública de educação e(m) saúde - Primeira Infância Melhor (PIM/RS) - tal como foi implementada em um lócus específico - a cidade de Canoas -, a fim de apreender como o gênero funciona para organizar relações sociais de poder com base em um conjunto de significados e símbolos construídos. Assim, enquanto as crianças público-alvo do PIM são tomadas como vulneráveis, as famílias pobres, representadas pelas mulheres-mães, precisam assimilar ensinamentos apoiados em esquemas teóricos e científicos capazes de produzir uma determinada posição de sujeito - o da mãe-professora.

Palavras-chave: gênero; maternidade; políticas públicas.

\section{Education of poor mothers for a "better childhood"}

This paper analyzes both the production and spread of some teachings directed to poor families and how they fundamentally positioned women as "naturally" and culturally loving, educating and nurturing mothers, by making them almost completely responsible for the family's health prevention and care, as well as for the generation of a "better childhood". Ethnographic data were obtained in the context of a health education public policy-Better Early Childhood Development Program - as it was implemented in a specific locus - the city of Canoas - in order to understand how gender works to organize social power relations from a set of constructed meanings and symbols. Thus, while the target children of Better Early Childhood Development Program are taken as vulnerable, poor families, represented by mothers, have to assimilate teachings that are grounded on theoretical and scientific schema capable of producing a determined subject position - that of the teacher-mother.

Keywords: gender; motherhood; public policies. 


\section{Educación de mujeres-madres pobres para una "infancia mejor"}

Este articulo analiza la transmisión y producción de algunas enseñanzas direccionadas a familias pobres y cómo se posicionaba las mujeres, fundamentalmente, como madres amorosas, educadoras y nutrices "naturales" y culturales de los niños, responsabilizándolas, casi integralmente, por la prevención y cuidado de la salud de la familia y por la generación de la "infancia mejor". Los datos etnográficos se obtuvieron en el contexto de una política pública de educación e(n) salud - Primera Infancia Mejor tal como la implementaron en un locus específico - la ciudad de Canoas -, con el objetivo de aprehender cómo funciona el género para organizar relaciones sociales de poder desde un conjunto de significados y simbolos construidos. Así, mientras que los niños del público destinatario del Primera Infancia Mejor son considerados vulnerables, las familias pobres, representadas por las mujeres-madres, tienen que asimilar enseñanzas apoyadas en esquemas teóricos y científicos que puedan producir una determinada posición de sujetode la madre-profesora.

Palabras clave: género; maternidad; políticas públicas. 